\title{
Influence of MIF polymorphisms on CpG island hyper-methylation of CDKN2A in the patients with ulcerative colitis
}

\author{
Naoko Sakurai', Tomoyuki Shibata², Masakatsu Nakamura', Hikaru Takano', Tasuku Hayashi', Masafumi Ota', \\ Tomoe Nomura-Horita', Ranji Hayashi', Takeo Shimasaki', Toshimi Ostuka', Tomomitsu Tahara ${ }^{3}$ and \\ Tomiyasu Arisawa ${ }^{1 *}$ (D)
}

\begin{abstract}
Background: CDKN2A hypermethylation is among the major events associated with carcinogenesis and is also observed in non-neoplastic colonic mucosa in patients with ulcerative colitis (UC). Macrophage migration inhibitory factor (MIF) plays a crucial role in promoting gastrointestinal inflammation characteristic of UC. The aim of this study is to explore associations between CDKN2A methylation status and MIF polymorphisms (rs755622 and rs5844572).

Methods: One hundred and fifty-nine patients diagnosed with UC were enrolled in this study. The methylation status of $p 14^{A R F}$ and $p 16^{I N K 4 a}$ was determined by MSP; MIF genotypes were identified by PCR-SSCP.

Results: We found no differences with respect to mean age, gender, clinical type (chronic continuous or relapse/ remitting), or extent of disease among the patients with methylated and unmethylated p14 ${ }^{\text {ARF }}$ or $p 16^{\text {INK } 4 a}$. Carrying the rs755622 C allele indicated a significantly higher risk for $p 14^{A R F}$ methylation (odds ratio (OR), 2.16; 95\% confidence interval $(\mathrm{Cl}), 1.08-4.32 ; p=0.030)$; similarly, carrying the rs5844572 7-repeat allele indicated a significantly higher risk for $p 16^{\mathrm{INK} 4 a}$ methylation $(\mathrm{OR}, 2.57 ; 95 \% \mathrm{Cl}, 1.26-5.24 ; p=0.0094)$ after an adjusted regression analysis. The carriers of the rs755662 C allele or the rs5844572 7-repeat allele were both at a significantly higher risk for methylation of both $p 14^{A R F}$ and $p 16^{1 N K 4 a}$ when compared to the cohort in which neither of the genes were methylated (OR, 2.70; 95\% Cl, 1.22-6.01; $p=0.015$ and $\mathrm{OR}, 2.87 ; 95 \% \mathrm{Cl}, 1.25-6.62 ; p=0.013$, respectively). Additionally, carrying rs755622 C allele was significantly associated with CIHM in chronic continuous of clinical type and total colitis (OR, 25.9; 95\% Cl, 2.55-262.6; $p=0.0059$ and $\mathrm{OR}, 4.38 ; 95 \% \mathrm{Cl}, 1.12-17.2 ; p=0.034$, respectively), and carrying 7-repeat allele of rs 5844572 was significantly associated in chronic continuous type $(\mathrm{OR}, 14.5 ; 95 \% \mathrm{Cl}, 1.46-$ 144.3; $p=0.022$ ).
\end{abstract}

Conclusions: Taken together, our findings suggest that MIF genotypes associated with inflammation may also be involved in promoting carcinogenesis via CDKN2A hypermethylation in patients diagnosed with UC.

Keywords: Ulcerative colitis, CDKN2A, CpG hypermethylation, Macrophage migration inhibitory factor, Genetic polymorphism

\footnotetext{
* Correspondence: tarisawa@kanazawa-med.ac.jp

'Department of Gastroenterology, Kanazawa Medical University, 1-1, Daigaku, Uchinada-machi, Ishikawa 920-0293, Japan

Full list of author information is available at the end of the article
}

(c) The Author(s). 2020 Open Access This article is licensed under a Creative Commons Attribution 4.0 International License, which permits use, sharing, adaptation, distribution and reproduction in any medium or format, as long as you give appropriate credit to the original author(s) and the source, provide a link to the Creative Commons licence, and indicate if changes were made. The images or other third party material in this article are included in the article's Creative Commons licence, unless indicated otherwise in a credit line to the material. If material is not included in the article's Creative Commons licence and your intended use is not permitted by statutory regulation or exceeds the permitted use, you will need to obtain permission directly from the copyright holder. To view a copy of this licence, visit http://creativecommons.org/licenses/by/4.0/ The Creative Commons Public Domain Dedication waiver (http://creativecommons.org/publicdomain/zero/1.0/) applies to the data made available in this article, unless otherwise stated in a credit line to the data. 


\section{Background}

Ulcerative colitis (UC) is nonspecific inflammation of the large intestine with unknown etiology and its inflammation may involve the colonic mucosa spanning from the rectum to the cecum [1]. UC patients have a chronic or remission/relapsing course and many inflammationor immune- related factors attribute to the severity of inflammation. Macrophage migration inhibitory factor (MIF) was initially identified as a factor released by $\mathrm{T}$ cells that inhibits the random migration of macrophages [2]. Subsequent studies revealed that MIF is a proinflammatory factor, which has important roles in various chronic inflammatory diseases and immune disorders, including UC [3, 4]. In particular, Ishiguro et al. reported that MIF contributes to steroid resistance of refractory $\mathrm{UC}$ via activator protein (AP)-1 signaling [5]. Two distinct polymorphisms were identified in MIF: rs755622 (- $173 \mathrm{G}>\mathrm{C}$ ) and rs5844572 (- 794 CATT tandem repeat), that were found to be in linkage disequilibrium [6]. Our previous study revealed that these genetic polymorphisms had little influence on the susceptibility to UC [7]; however, a recent meta-analysis based on recessive and co-dominant genetic models identified a significant relationship linking the rs755622 polymorphism and susceptibility to disease [8,9]. As such, the MIF genotype seems to influence the development and progression of UC.

Recent advances with respect to our understanding the pathogenesis of UC together with the development of new therapeutic agents have introduced the possibility of disease control in many cases of UC [10]. However, as the incidence of colitis-associated-cancer (CAC) increases among patients with UC in proportion to the duration of the disease $[11,12]$, prevention of carcinogenesis and identification of high-risk groups are currently essential clinical issues. Generally, important risk factors for development of CAC are the existence of extensive colonic lesions [11], longer duration of disease [12], positive family history of colorectal cancers [13, 14] and the presence of histologically-active inflammation [15]. However, the risk factors underlying UC-associated carcinogenesis require further and ongoing clarification. CpG island hypermethylation (CIHM) is a critical mechanism that promotes gene inactivation and is commonly observed in association with numerous human cancers [16]. Additionally, CIHM of several specific genes, a phenomenon known as age-related methylation, was also detected in non-neoplastic tissues [17]; this type of methylation has been related to precancerous states [18]. CIHM has been reported within non-neoplastic colonic mucosal tissues of patients diagnosed with UC; likewise, chronic inflammation has been shown to promote agerelated methylation [19]. Our previously study also revealed aberrant methylation of the tumor suppressors $p 14^{A R F}$ and $p 16^{I N K 4 a}$, both encoded by Cyclin Dependent Kinase Inhibitor 2A (CDKN2A) locus, in the nonneoplastic colonic mucosal tissues of patients with UC [20].

As such, we considered the possibility of identifying patients at high risk for the development of CAC by examining the impact of specific genotypes on CIHM of the genes associated with precancerous states. In the current study, we explored the relationship between polymorphisms of $M I F$, a gene encoding a proinflammatory mediator associated with UC, and CIHM of $p 14^{A R F}$ and $p 16^{I N K 4 a}$. Our goal was to determine whether the MIF gene polymorphisms have any implications for the assessment of UC patients at high risk for carcinogenesis.

\section{Methods}

Patients and samples

One hundred and fifty-nine patients with UC were enrolled in this study. All patients were treated at the Endoscopic Center of Fujita Health University Hospital, registered from January 2006 to December 2012. UC was diagnosed according to the standard criteria such as clinical, endoscopic, and histological features [21]. When colonoscopy was performed, the biopsy specimens of inflammatory mucosa were obtained from the rectum of all patients and reserved in $-80{ }^{\circ} \mathrm{C}$. All patients were in endoscopic remission clinically but mild or moderate inflammation without evidence of dysplasia or neoplasia was shown by histopathological examinations showed in all cases. Genomic DNA was isolated using the FlexiGene DNA Kit (QIAGEN GmbH, Hilden, Germany) from peripheral blood obtained at the same time as colonoscopy. The protocol for the present study was approved by the Ethics Committee of Fujita Health University (HM18-094), and written consent was obtained in all cases.

\section{Classifications}

The enrolled patients were classified into two groups, including chronic continuous and relapse/remitting phenotypes, according to their previous clinical course [22]. Patients were also classified by endoscopic features as total or subtotal (distal or left side) colitis according to the location and extent of the inflammatory lesions.

\section{Detection of DNA methylation of $p 14^{A R F}$ and $p 16^{I N K 4 a}$ by methylation-specific PCR method (MSP)}

CIHM of $p 14^{A R F}$ and $p 16^{I N K 4 a}$ was assessed according to the method previously described [23]. We treated genomic DNA, which extracted from rectal biopsy specimens using proteinase $\mathrm{K}$, with sodium bisulfite using the BislFast DNA Modification Kit for methylated DNA Detection (Toyobo, Co., Ltd., Osaka, Japan). The primer sets used at MSP were shown in Table 1. We determined the annealing 
Table 1 Primer sets used in this study

\begin{tabular}{|c|c|}
\hline \multicolumn{2}{|c|}{ Primer sets for MSP } \\
\hline P14-UM_F & 5'-gagtttggttttggaggtgg-3' \\
\hline p14-UM_R & 5'-aасcасаacaacaaacacccct-3' \\
\hline P14-M_F & 5'-tgagtttggttttggaggtgg-3' \\
\hline p14-M_R & 5'-aaaaccacaacgacgaacg-3' \\
\hline p16-UM_F & 5'-ttattagagggtggggtggattgt-3' \\
\hline p16-UM_R & 5'-caaccccaaaccacaaccataa-3' \\
\hline P16-M_F & 5'-ttattagagggtggggcggatcgc-3' \\
\hline p16-M_R & 5'-accccgaaccgcgaccgtaa-3' \\
\hline \multicolumn{2}{|c|}{ Primer sets for MIF polymorphism detection } \\
\hline rs755622_F & $5^{\prime}$-tctagccgccaagtggagaaca-3' \\
\hline rs755622_R & $5^{\prime}$-actgtggtcccgecttttgtga-3' \\
\hline rs5844572_F & $5^{\prime}$-tgatccagttgctgccttgtc-3' \\
\hline rs5844572_R & 5'-tccactaatggtaaactcggggac- $3^{\prime}$ \\
\hline
\end{tabular}

MSP Methylation specific RCR, UM Unmethylated, $M$ Methylated, $F$ Forward, $R$ Reverse

temperature and times using DNA from peripheral blood of a young individual (as an unmethylated control) and its DNA treated with SssI methylase (methylated control; New England BioLabs Inc., Beverly, MA, USA). Using EX Taq HS (Takara Bio, Shiga, Japan), the PCR was performed with the addition of $0.1 \mu \mathrm{g}$ of bisulfite-modified DNA in $20 \mu \mathrm{L}$ of a buffer. The PCR condition were an initial denaturing step of $5 \mathrm{~min}$ at $95^{\circ} \mathrm{C}$, followed by 33 cycles of $30 \mathrm{~s}$ denaturing at $95^{\circ} \mathrm{C}, 1 \mathrm{~min}$ annealing at $64-68^{\circ} \mathrm{C}$ according to primers used, and $1 \mathrm{~min}$ extension at $72{ }^{\circ} \mathrm{C}$, and a final 5 min extension step at $72{ }^{\circ} \mathrm{C}$. To detect the band of MSP sample, we performed electrophoresis of PCR products in 3.0\% agarose gels stained with ethidium bromide. Then, fluorescence intensity of UV illumination was measured by a digital densitometer. The methylation ratio was calculated as the ratio of intensities of the methylated band to methylated plus unmethylated bands, and a ratio more than $50 \%$ was judged as significantly methylated.

\section{Genotyping of MIF polymorphisms}

The genotype of MIF polymorphisms was determined by the polymerase chain reaction (PCR)-single-strand conformation polymorphism (SSCP) method as described previously [7]. The primer sets used were shown in Table 1. The PCR was performed using EX Taq HS (Takara Bio, Shiga, Japan), adding $0.1 \mu \mathrm{g}$ of genomic DNA extracted from peripheral blood to $20 \mu \mathrm{L}$ of a buffer, denaturing at $95^{\circ} \mathrm{C}$ for $3 \mathrm{~min}$, followed by 35 cycles of $15 \mathrm{~s}$ at $96^{\circ} \mathrm{C}, 40 \mathrm{~s}$ at $60^{\circ} \mathrm{C}$ for rs 755622 or $62^{\circ} \mathrm{C}$ for rs5844572, and $30 \mathrm{~s}$ at $72^{\circ} \mathrm{C}$, and $5 \mathrm{~min}$ final extension at $72{ }^{\circ} \mathrm{C}$. Then, $2 \mu \mathrm{L}$ of the PCR product was treated in $10 \mu \mathrm{L}$ of formamide for $5 \mathrm{~min}$ at $90^{\circ} \mathrm{C}$ and denatured to a single strand. SSCP was performed in Gene Phor DNA separation system using the Gene Gel Excel 12.5/24 kit
(GE Health Care Bio-Sciences AB, Stockholm, Sweden) at a constant temperature of $6^{\circ} \mathrm{C}$, and the denatured bands were detected using the DNA silver staining kit (GE Health Care Bio-Sciences AB).

\section{Statistical analysis}

The Hardy-Weinberg equilibrium (HWE) was assessed by $X^{2}$ statistics. Mean age was expressed as mean $\pm S D$ and analyzed by Student's t-test. The ratio of sex and CIHM frequencies was compared by Fisher's exact test. Allele counts and genotype distribution were also compared between two groups by Fisher's exact test. The odds ratio (OR) and 95\% confidence intervals (CI) for the strength of genotype involvement in CIHM were calculated using a logistic regression analysis adjusted for age, sex, clinical type and disease extension. A probability value of less than 0.05 was considered statistically significant in all analyses. Stata software (version 13; StataCorp LP, College Station, TX, USA) was used for statistical processing.

\section{Results}

\section{Demographic characteristics, allelic frequencies, and} CDKN2A methylation status

The characteristics and allele frequencies observed among the UC patients enrolled in this study are shown in Table 2. The allele distribution of MIF (rs755622) met the criteria for HWE $(p=1.00)$. We found no differences with respect to mean age, gender, clinical type, or extent of disease among those with methylated and unmethylated $p 14^{A R F}$ or $p 16^{I N K 4 a}$. The minor allele frequency of rs755622 was somewhat higher in the group with $p 14^{A R F}$ methylation; of note, the frequency of the $C$ allele carrier was significantly higher $(p=0.01)$. By contrast, no significant differences in the minor allele frequencies associated with rs755622 were observed when comparing the $p 16^{I N K 4 a}$ methylated and unmethylated groups. Similarly, the 7-repeat allele frequency of rs5844572 was significantly higher in the $p 16^{I N K 4 a}$ methylated group compared to unmethylated group $(p=0.036)$, but no significant differences were observed when comparing the $p 14^{A R F}$ methylated with unmethylated groups.

\section{Association between MIF polymorphisms and methylation status of $p 14^{A R F}$ or $p 16^{I N K 4 a}$}

By a logistic regression analysis after adjusting for confounding factors including age, gender, clinical type, and extent of disease, carrying $C$ allele of rs755622 was significantly associated with CIHM of $p 14^{A R F}$ (Table 3; OR, 2.16; 95\% CI, 1.08-4.32; $p=0.030$ ). By contrast, no significant relationship was found between $p 16^{I N K 4 a}$ methylation and the allele frequencies associated with rs755622. The rs755622 CC homozygous was not 
Table 2 Demographic characteristics, allelic frequencies, and CDKN2A methylation status

\begin{tabular}{|c|c|c|c|c|c|c|c|}
\hline & Overall UC & p14-UM & p14-M & $p^{a}$ & p16-UM & p16-M & $\mathbf{p}^{\mathbf{b}}$ \\
\hline Number of sample & 159 & 105 & 54 & & 89 & 70 & \\
\hline Mean age \pm SD & $41.3 \pm 13.6$ & $40.4 \pm 13.4$ & $43.0 \pm 14.0$ & NS & $42.1 \pm 15.2$ & $40.2 \pm 11.3$ & NS \\
\hline Male: female & 91: 68 & 66: 39 & $25: 29$ & NS & 50: 39 & 41: 29 & NS \\
\hline Clinical type & & & & NS & & & NS \\
\hline Chronic continuous & 56 & 38 & 18 & & 31 & 25 & \\
\hline Relapse/remitting & 103 & 67 & 36 & & 58 & 45 & \\
\hline Disease extension & & & & NS & & & NS \\
\hline Total colitis & 74 & 49 & 25 & & 35 & 39 & \\
\hline Distal or left side colitis (rs755622 G > C) & 85 & 56 & 29 & & 54 & 31 & \\
\hline GG & 93 & 68 & 25 & 0.010 & 57 & 36 & NS \\
\hline GC & 57 & 32 & 25 & & 28 & 29 & \\
\hline $\mathrm{CC}$ & 9 & 5 & 4 & NS & 4 & 5 & NS \\
\hline C allele freqency (rs5844572 CATT repeat) & $23.6 \%$ & $20.0 \%$ & $30.6 \%$ & 0.050 & $20.2 \%$ & $27.9 \%$ & NS \\
\hline $5 / 5$ & 16 & 13 & 3 & & 9 & 7 & \\
\hline $5 / 6$ & 57 & 40 & 17 & & 31 & 26 & \\
\hline $5 / 7$ & 28 & 16 & 12 & & 12 & 16 & \\
\hline $6 / 6$ & 28 & 19 & 9 & & 23 & 5 & \\
\hline $6 / 7$ & 23 & 14 & 9 & & 12 & 11 & \\
\hline $7 / 7$ & 7 & 3 & 4 & & 2 & 5 & \\
\hline 5 repeat freqency & $36.8 \%$ & $39.0 \%$ & $32.4 \%$ & & $34.3 \%$ & $40.0 \%$ & \\
\hline 6 repeat freqency & $42.8 \%$ & $43.8 \%$ & $40.7 \%$ & & $50.0 \%$ & $42.1 \%$ & \\
\hline 7 repeat freqency & $20.4 \%$ & $17.1 \%$ & $26.9 \%$ & NS & $15.7 \%$ & $26.4 \%$ & 0.036 \\
\hline
\end{tabular}

p14-UM, $p 14^{A R F}$ unmethylated; $\mathrm{p} 14-\mathrm{M}, \mathrm{p} 14^{A R F}$ methylated; $\mathrm{p} 16-\mathrm{UM}, \mathrm{p} 16^{\text {INK4a }}$ unmethylated;

p16-M, p16 ${ }^{\text {INK4a }}$ methylated; a $\mathrm{p} 14-U M$ vs. p14-M; ${ }^{b}$ p16-UM vs. p16-M; NS Not significant

associated with CIHM of both $p 14^{A R F}$ and $p 16^{I N K 4 a}$ by a recessive genetic model.

We previously revealed that CATT 7-repeat allele of rs5844572 promotes inflammation. Thus, we assessed the influence of the 7-repeat allele. Our findings indicate that carrying the rs5844572 7-repeat allele was a significant risk factor for $p 16^{I N K 4 a}$ methylation by an adjusted logistic regression analysis (Table 4; OR, 2.57; 95\% CI, 1.26-5.24; $p=$ 0.0094). By contrast, there were no significant relationships between $p 14^{A R F}$ methylation and rs5844572 allele frequencies. The homozygous of rs5844572 7-repeat allele was not associated with CIHM of both $p 14^{A R F}$ and $p 16^{I N K 4 a}$.
Demographic characteristics and allele frequencies of subjects demonstrating no methylation or methylation of both $p 14^{A R F}$ and $p 16^{\text {INK4a }}$

Comparisons among groups demonstrating methylation of both $p 14^{A R F}$ and $p 16^{I N K 4 a}$ with those in which both were unmethylated are shown in Table 5 . The allele distribution of MIF (rs755622) in both methylated and neither methylated groups met the criteria for HWE ( $p=0.73$ and $p=0.72$, respectively). There were no significant differences with respect to clinicopathological backgrounds between these two groups.

Table 3 Association between MIF rs755622 and CDKN2A methylation

\begin{tabular}{|c|c|c|c|c|c|}
\hline & \multicolumn{3}{|c|}{ Genotype } & \multirow{2}{*}{$\begin{array}{l}\text { GG vs. } \mathrm{GC}+\mathrm{CC} \\
\text { adjusted } \mathrm{OR}^{*}(95 \% \mathrm{Cl}) ; p \text { value }\end{array}$} & \multirow{2}{*}{$\begin{array}{l}\text { GG + GC vs. CC } \\
\text { adjusted } \mathrm{OR}^{*}(95 \% \mathrm{Cl}) ; p \text { value }\end{array}$} \\
\hline & GG & GC & $\mathrm{CC}$ & & \\
\hline p14-UM (105) & 68 & 32 & 5 & reference & reference \\
\hline p14-M (54) & 25 & 25 & 4 & $2.16(1.08-4.32) ; p=0.030$ & $2.30(0.52-10.3) ; p=0.27$ \\
\hline p16-UM (89) & 57 & 28 & 4 & reference & reference \\
\hline p16-M (70) & 36 & 29 & 5 & $1.90(0.974-3.69) ; p=0.060$ & $2.25(0.52-9.69) ; p=0.28$ \\
\hline
\end{tabular}

*by logistic regression analysis after adjustment for age, gender, clinical type and disease extension UM Unmethylated, M Methylated 
Table 4 Association between MIF rs5844572 and CDKN2A methylation

\begin{tabular}{|c|c|c|c|c|c|c|c|c|}
\hline & \multicolumn{6}{|c|}{ Genotype (repeat number) } & \multirow{2}{*}{$\begin{array}{l}X / X \text { vs. } X / 7+7 / 7 \\
\text { adjusted } O R^{*}(95 \% \mathrm{Cl}) ; p \text { value }\end{array}$} & \multirow{2}{*}{$\begin{array}{l}X / X+X / 7 \text { vs. } 7 / 7 \\
\text { adjusted } \mathrm{OR}^{*}(95 \% \mathrm{Cl}) ; p \text { value }\end{array}$} \\
\hline & $5 / 5$ & $5 / 6$ & $5 / 7$ & $6 / 6$ & $6 / 7$ & $7 / 7$ & & \\
\hline p14-UM (105) & 13 & 40 & 16 & 19 & 14 & 3 & reference & reference \\
\hline p14-M (54) & 3 & 17 & 12 & 9 & 9 & 4 & $1.77(0.864-3.63) ; p=0.12$ & $4.51(0.79-25.7) ; p=0.090$ \\
\hline p16-UM (89) & 9 & 31 & 12 & 23 & 12 & 2 & reference & reference \\
\hline p16-M (70) & 7 & 26 & 16 & 5 & 11 & 5 & $2.57(1.26-5.24) ; p=0.0094$ & $5.51(0.90-33.9) ; p=0.066$ \\
\hline
\end{tabular}

*by logistic regression analysis after adjustment for age, gender, clinical type and disease extension

UM Unmethylated, $M$ Methylated, X: 5 or 6 repeat allele; 7: 7 repeat allele

The minor allele frequencies associated with rs755622 were significantly higher in the group in which both $p 14^{A R F}$ and $p 16^{I N K 4 a}$ were methylated compared to the fully unmethylated group $(p=0.029)$; the $\mathrm{C}$ allele carrier was detected at significantly higher frequency $(p=0.020)$. Similarly, the frequency of the rs5844572 7-repeat allele was significantly higher in the group in which both $p 14^{A R F}$ and $p 16^{I N K 4 a}$ were methylated compared to the fully unmethylated group $(p=0.0090)$.

\section{Association between MIF polymorphisms and CDKN2A methylation}

The results of an analysis in which confounding factors were adjusted revealed that carrying the rs755622 $\mathrm{C}$ allele and the rs5844572 7-repeat allele was significantly associated with an increased methylation of both $p 14^{A R F}$ and $p 16^{I N K 4 a}$ (OR, 2.70; 95\% CI, 1.22-6.01; $p=0.015$ and OR, 2.87; 95\% CI, 1.25-6.62; $p=0.013$, respectively; Table 6). In addition, homozygous of rs5844572 7-repeat allele was significantly associated with CIHM of both genes (OR, 12.0; 95\%CI, 1.55-92.2; $p=0.017$ ).

Table 5 Demographic characteristics and allele frequencies of subjects demonstrating no methylation or methylation of both $p 14^{A R F}$ and $p 16^{I N K 4 a}$

\begin{tabular}{|c|c|c|c|}
\hline & Neither methylated & Both methylated & $p$ value \\
\hline Number of sample & 77 & 42 & \\
\hline Mean age \pm SD & $41.6 \pm 14.9$ & $42.5 \pm 12.9$ & NS \\
\hline Male: female & 46: 31 & $21: 21$ & NS \\
\hline Clinical type & & & NS \\
\hline Chronic continuous & 25 & 12 & \\
\hline Relapse/remitting & 52 & 30 & \\
\hline Extension & & & NS \\
\hline Total colitis & 31 & 21 & \\
\hline Distal or left side colitis (rs755622 G > C) & 46 & 21 & \\
\hline GG & 49 & 17 & 0.020 \\
\hline GC & 24 & 21 & \\
\hline $\mathrm{CC}$ & 4 & 4 & NS \\
\hline C allele freqency (rs5844572 CATT repeat) & $20.8 \%$ & $34.5 \%$ & 0.029 \\
\hline $5 / 5$ & 7 & 1 & \\
\hline $5 / 6$ & 27 & 13 & \\
\hline $5 / 7$ & 12 & 12 & \\
\hline $6 / 6$ & 19 & 5 & \\
\hline $6 / 7$ & 10 & 7 & \\
\hline $7 / 7$ & 2 & 4 & \\
\hline 5 repeat freqency & $34.4 \%$ & $32.1 \%$ & \\
\hline 6 repeat freqency & $48.7 \%$ & $35.7 \%$ & \\
\hline 7 repeat freqency & $16.9 \%$ & $32.1 \%$ & 0.0090 \\
\hline
\end{tabular}

$p$ value: unmethylated vs. both methylated 
Table 6 Association between MIF polymorphisms and CDKN2A methylation

\begin{tabular}{|c|c|c|}
\hline \multirow[t]{2}{*}{ rs755622 } & GG vs. GC+CC & GG + GC vs. CC \\
\hline & adjusted $\mathrm{OR}^{*}(95 \% \mathrm{Cl}) ; p$ value & adjusted $\mathrm{OR}^{*}(95 \% \mathrm{Cl}) ; p$ value \\
\hline Neither methylated (77) & reference & reference \\
\hline Both methylated (42) & $2.70(1.22-6.01) ; p=0.015$ & $3.92(0.76-20.3) ; p=0.10$ \\
\hline \multirow[t]{2}{*}{ rs5844572 } & $X / X$ vs. $X / 7+7 / 7$ & $X / X+X / 7$ vs. $7 / 7$ \\
\hline & adjusted OR* (95\% C.I.); $p$ value & adjusted $\mathrm{OR}^{*}(95 \%$ C.I.); $p$ value \\
\hline Neither methylated (77) & reference & reference \\
\hline Both methylated (42) & $2.87(1.25-6.62) ; p=0.013$ & $12.0(1.55-92.2) ; p=0.017$ \\
\hline
\end{tabular}

*by logistic regression analysis after adjustment for age, gender, clinical type and disease extension

$\mathrm{X}$ : 5 or 6 repeat allele; 7: 7 repeat allele

\section{Association between MIF polymorphisms and CDKN2A methylation in phenotype of UC}

Next, we investigated in what kind of UC phenotype the significant association of MIF polymorphisms with CIHM of CDKN2A was seen (Table 7). Carrying rs755622 C allele was significantly associated with CIHM in chronic continuous of clinical type and total colitis (OR, 25.9; 95\% CI, 2.55-262.6; $p=0.0059$ and OR, 4.38; 95\% CI, 1.12-17.2; $p=0.034$, respectively). Meanwhile, carrying 7-repeat allele of rs5844572 was significantly associated in chronic continuous type (OR, 14.5; 95\%CI, $1.46-144.3 ; p=0.022)$.

Table 7 Association between MIF polymorphisms and CDKN2A methylation in UC phenotype

\begin{tabular}{|c|c|c|c|}
\hline rs755622 & geno & & \\
\hline Chronic continuous & GG & GC & C \\
\hline Neither methylated (25) & 17 & 6 & 2 \\
\hline Both methylated (12) & 2 & 6 & 4 \\
\hline Relapse/remitting & GG & GC & $C$ \\
\hline Neither methylated (52) & 32 & 18 & 2 \\
\hline Both methylated (30) & 15 & 15 & 0 \\
\hline Total colitis & GG & GC & C \\
\hline Neither methylated (31) & 21 & 10 & 0 \\
\hline Both methylated (21) & 9 & 12 & 0 \\
\hline Distal or left side colitis & GG & GC & C \\
\hline Neither methylated (46) & 28 & 14 & 4 \\
\hline Both methylated (21) & 8 & 9 & 4 \\
\hline rs5844572 & geno & & \\
\hline Chronic continuous & $X / X$ & $X / 7$ & 7) \\
\hline Neither methylated (25) & 15 & 8 & 2 \\
\hline Both methylated (12) & 3 & 5 & 4 \\
\hline Relapse/remitting & $X / X$ & $\mathrm{X} / 7$ & 7/ \\
\hline Neither methylated (52) & 38 & 14 & 0 \\
\hline Both methylated (30) & 16 & 14 & 0 \\
\hline Total colitis & $X / X$ & $\mathrm{X} / 7$ & $7 /$ \\
\hline Neither methylated (31) & 21 & 10 & 0 \\
\hline Both methylated (21) & 10 & 11 & 0 \\
\hline Distal or left side colitis & $X / X$ & $X / 7$ & 7) \\
\hline Neither methylated (46) & 32 & 12 & 2 \\
\hline Both methylated (21) & 9 & 8 & 4 \\
\hline
\end{tabular}

adjusted OR (95\% C.I.); $p$ value

GG vs. GC+CC

reference

$25.9(2.55-262.6) ; p=0.0059^{a}$

GG vs. GC+CC

reference

$1.93(0.732-5.07) ; p=0.18^{\mathrm{a}}$

GG vs. GC+CC

reference

$4.38(1.12-17.2) ; p=0.034^{b}$

GG vs. GC+CC

reference

$2.75(0.899-8.43) ; p=0.076^{b}$

adjusted OR (95\% C.I.); $p$ value

$X / X$ vs. $X / 7+7 / 7$

reference

$14.5(1.46-144.3) ; p=0.022^{\mathrm{a}}$

$\mathrm{X} / \mathrm{X}$ vs. $\mathrm{X} / 7+7 / 7$

reference

$2.64(0.970-7.17) ; p=0.058^{\mathrm{a}}$

$X / X$ vs. $X / 7+7 / 7$

reference

$3.47(0.895-13.4) ; p=0.072^{b}$

$X / X$ vs. $X / 7+7 / 7$

reference

$2.89(0.931-8.98) ; p=0.066^{\mathrm{b}}$ 


\section{Discussion}

In the present study, we investigated the impact of MIF gene polymorphisms on aberrant methylation in the promoter regions of $p 14^{A R F}$ and $p 16^{I N K 4 a}$, each generated by alternative splicing at the CDKN2A locus, in a cohort of 159 patients diagnosed with UC. Our results revealed that MIF rs755622 C and rs5844572 7-repeat alleles were associated with $p 14^{A R F}$ and $p 16^{I N K 4 a}$ methylation, respectively. Furthermore, the rs755622 $\mathrm{C}$ and rs5844572 7-repeat alleles were both associated with enhanced CDKN2A methylation among patients in which both $p 14^{A R F}$ and $p 16^{I N K 4 a}$ were methylated compared to those in which neither of the sites were methylated using a dominant genetic model. We suspect that no significant association between homozygous of both genotypes and CIHM of CDKN2A based on a recessive genetic model may be due to a small number of subjects in this study.

MIF is a proinflammatory cytokine that promotes recruitment of neutrophils and macrophages to inflammatory foci in the setting of inflammatory disease [24]. Several studies have focused on MIF as a key molecule promoting pathogenesis of a diverse array of diseases, including rheumatoid arthritis [25] and septic shock [26]. MIF is also a critical mediator of UC [4, 5, 27]. Renner et al. reported that polymorphisms in the human MIF gene were associated with susceptibility to and severity of several inflammatory diseases, including UC [6]. Likewise, Donn et al. revealed by promoter sequence analysis that change of $\mathrm{G}$ to $\mathrm{C}$ at -173 (rs755622) has a direct impact on MIF expression as it creates a potential binding site for the transcription factor, AP-4; transcriptional activity of the MIF gene increases in accordance with the number of sequence repeats associated with the rs5844572 polymorphism [28]. Similarly, Amoli et al. reported that a MIF promoter with rs5844572 5-repeat was less transcriptionally active than those with 6 - and 7-repeats [29]. In GTEx portal site (https://gtexportal. org/), an increased number of rs755622 minor allele correlates to the increased expression of MIF, although the data of rs5844572 is not shown. Since the rs755622 C and rs5844572 7-repeat alleles are in strong linkage disequilibrium [6], the combination of these two alleles may constitute an inflammatory haplotype. This is consistent with the reported associations linking the rs755622 C- and rs5844572 7-repeat haplotype with susceptibility to juvenile idiopathic arthritis [28] as well as to findings in our previous studies focused on gastric inflammation and carcinogenesis [30, 31]. However, in our previous study [7], genetic polymorphisms in MIF were not strongly associated with susceptibility to UC; likewise, Nohara et al. reported no differences with respect to the distribution of the rs755622 genotype when comparing findings from healthy subjects to those diagnosed with UC patients from the general Japanese population
[32]. The results of these studies suggest that the proinflammatory haplotype of MIF may not be significantly involved in susceptibility to $\mathrm{UC}$ in the Japanese population.

The $\mathrm{p} 14^{\mathrm{ARF}}$ and $\mathrm{p} 16^{\mathrm{INK} 4 \mathrm{a}}$ proteins are encoded by $C D K N 2 A$ by alternative splicing; these proteins act on the p53 and pRb pathways, respectively, to promote negative regulation of the cell cycle [33, 34]. As such, methylationmediated silencing of gene expression may have important implications with respect to carcinogenesis. Poi et al. have shown that methylation at each promoter site has resulted in gene deletion or silencing in association with several cancers [35]. Conversely, gene methylation has been associated with chronic inflammation [36], and methylation of both $p 14^{A R F}$ and $p 16^{I N K 4 a}$ is already enhanced in non-neoplastic colonic mucosa of patients with UC [37, $38]$. Of these two loci, methylation at $p 16^{I N K 4 a}$ seems to be of greater importance with respect to the development of CAC [39]. However, methylation at $p 14^{A R F}$ may also have important implications; methylation of both $p 14^{A R F}$ and $p 16^{I N K 4 a}$ was reported among the more invasive forms of sporadic colorectal cancer [40]. Our present observations revealed a significant relationship between the proinflammatory allele of MIF and methylation of both $p 14^{A R F}$ and $p 16^{I N K 4 a}$ in the colonic mucosa of patients diagnosed with UC. These findings stand in contrast to those reported in our previous study [7], in which we found that these alleles were not significantly associated with susceptibility to UC. Taken together, we infer from these results that carrying the proinflammatory allele of MIF may be involved in the intensity of inflammation observed after the onset of UC among those in the Japanese population; this allele may not be involved in the development of UC, but is involved in promoting CDKN2A methylation. Although it is unclear whether methylation at these sites is directly involved in the development of $\mathrm{CAC}$ in patients with $\mathrm{UC}$, it remains possible that individuals carrying an inflammatory allele in $M I F$ may be at higher risk for this complication. Furthermore, in our results, the significant association of MIF polymorphisms with CIHM of CDKN2A were found in chronic continuous of clinical type and total colitis phenotype. Rogler has been reported continuous severe inflammation is involved in the development of CAC in UC [41]. Meanwhile, it is well known that the extent of inflammatory colonic mucosa is related to the increased risk for the development of CAC in UC [12]. These facts suggest that the patients with chronic continuous phenotype and total colitis of UC have a higher risk for development of CAC than with relapse/remitting phenotype and left sided/ distal colitis of UC, respectively. MIF polymorphisms may contribute to further increasing the high risk for the development of CAC via CIHM of CDKN2A. 
In our present study, we focused on the CIHM of $C D K N 2 A$. However, there is possibility that CpG islands of many other genes are methylated in inflammatory mucosa of UC. Recently, Tahara, one of the co-authors in this study, revealed a high rate of hypermethylation in the severe phenotype of $\mathrm{UC}$, particularly at the $\mathrm{CpG}$ islands, by genome-wide methylation analysis, and that these methylated genes were related to those involved in biosynthetic processes, the regulation of metabolic processes, and nitrogen compound metabolic processes [42]. In addition, we have already reported that function gain genotypes of various immune- or inflammationrelated molecules were associated with an increased CpG methylation of $C D H 1$, encoding e-cadherin, and CDKN2A [20, 43]. Further studies for an association of various genotypes with $\mathrm{CpG}$ islands methylation of the responsible genes for development of CAC will be needed.

There are various limitations to this study. First, the study a retrospective and utilized previously-stored tissue samples collected at a single institution in Japan. A multi-centered prospective study based on these findings should be conducted in the near future. Second, as this study was conducted using a small number of samples, we were unable to examine other gene polymorphisms that might influence the methylation status of the MIF gene. As above, a multi-centered study may provide more samples for evaluation. Third, patients enrolled in this study have taken various medications, not the same medications. In addition, since the onset age of our patients was partially unclear, the analysis could not be performed using disease duration as a co-variate. Finally, a full evaluation of the risk of developing CAC from UC would include patients with CAC as well as those diagnosed with a precancerous condition. Again, due to the very limited number of samples from patients who developed CAC at our institution, we were unable to study this phenomenon directly. As such, we included samples from patients with precancerous conditions as a next best practice.

\section{Conclusions}

In conclusion, our findings indicate that the rs755622 C-rs5844572 7-repeat MIF haplotype, which includes two distinct alleles that are in strong linkage disequilibrium, is significantly associated with increased methylation of both $p 14^{A R F}$ and $p 16^{I N K 4 a}$. These observations suggest that UC patients with this inflammatory genotype of $M I F$ may be at a higher risk for developing CAC.

\section{Abbreviations}

UC: Ulcerative colitis; MIF: Macrophage migration inhibitory factor; AP: Activator protein; CAC: Colitis-associated-cancer; CIHM: CpG island hypermethylation; CDKN2A: Cyclin Dependent Kinase Inhibitor 2A;

PCR: Polymerase chain reaction; MSP: Methylation-specific RCR; PCR-
SSCP: PCR- single-strand conformation polymorphism; HWE: Hardy-Weinberg equilibrium; OR: Odds ratio; Cl: Confidence interval; pRB: Retinoblastoma protein.

\section{Acknowledgments}

Not Applicable.

\section{Authors' contributions}

NS determined the genotype, analyzed the data and wrote the paper. TA was responsible for instructing on the scientific research and writing of the manuscript. MN, TO, HT, TH, MO, TN-H, RH and TS2 contributed to the literature review; data analysis; drafting, editing, and critical revision of the manuscript; and approval of the final version of the manuscript. TT and TS1 obtained the clinical samples and data, and participated in the design of the study. All authors have read and approved the final manuscript.

\section{Funding}

No funding was received.

\section{Availability of data and materials}

All data generated during this study are included in this published article. The raw data analyzed during the current study are not publicly available due to risk of compromising individual privacy. The application and the written consent forms state that the data will only be available to the researchers within the project. For inquires on the data, researchers should first reach out to the owner of the database, Fujita Health University. Please reach out to the corresponding author with requests and for assistance with data requests.

Ethics approval and consent to participate

The Ethics Committees of Fujita Health University approved the protocol (HM18-094), and all participants gave their written informed consent.

\section{Consent for publication}

Not applicable.

\section{Competing interests}

The authors declare that they have no competing interests.

\section{Author details}

${ }^{1}$ Department of Gastroenterology, Kanazawa Medical University, 1-1, Daigaku, Uchinada-machi, Ishikawa 920-0293, Japan. ²Department of Gastroenterology, Fujita Health University, 1-98, Dengakugakubo, Kutsukake-cho, Toyoake 470-1192, Japan. ${ }^{3}$ Department of Gastroenterology and Hepatology, Kansai Medical University, 2-5-1 Shin-machi, Hirakata, Osaka 573-1010, Japan.

Received: 11 August 2020 Accepted: 6 October 2020

Published online: 12 October 2020

\section{References}

1. Podolsky DK. Inflammatory bowel disease. N Engl J Med. 2002;347:417-29.

2. David JR. Delayed hypersensitivity in vitro: its mediation by cell-free substances formed by lymphoid cell-antigen interaction. Proc Natl Acad Sci U S A. 1966:56:72-7.

3. Lue H, Kleemann R, Calandra T, Roger T, Bernhagen J. Macrophage migration inhibitory factor (MIF): mechanisms of action and role in disease. Microb Infect. 2002;4:449-60.

4. Murakami H, Akbar SM, Matsui H, Horiike N, Onji M. Macrophage migration inhibitory factor activates antigen-presenting dendritic cells and induces inflammatory cytokines in ulcerative colitis. Clin Exp Immunol. 2002;128: 504-10.

5. Ishiguro Y, Yamagata K, Sakuraba H, Munakata A, Nakane A, Morita T, et al. Macrophage migration inhibitory factor and activator protein-1 in ulcerative colitis. Ann N Y Acad Sci. 2004;1029:348-9.

6. Renner P, Roger T, Calandra T. Macrophage migration inhibitory factor: gene polymorphisms and susceptibility to inflammatory diseases. Clin Infect Dis. 2005;41(Suppl 7):S513-9.

7. Shiroeda $H$, Tahara T, Nakamura M, Shibata T, Nomura T, Yamada $H$, et al. Association between functional promoter polymorphisms of macrophage migration inhibitory factor (MIF) gene and ulcerative colitis in Japan. Cytokine. 2010;51:173-7. 
8. Zhang H, Ma L, Dong LQ, Shu C, Xu JL. Association of the macrophage migration inhibitory factor gene $-173 \mathrm{G} / \mathrm{C}$ polymorphism with inflammatory bowel disease: a meta-analysis of 4296 subjects. Gene. 2013;526:228-31.

9. Shen Y, Guo S, Yang T, Jia L, Chen L, An J, et al. The -173 G/C polymorphism of the MIF gene and inflammatory bowel disease risk: a meta-analysis. Int J Mol Sci. 2013;14:11392-401.

10. Trigo-Vicente C, Gimeno-Ballester V, García-López S, López-Del VA. Systematic review and network meta-analysis of treatment for moderate-tosevere ulcerative colitis. Int J Clin Pharm. 2018;40:1411-9.

11. Ekbom A, Helmick C, Zack M, Adami HO. Ulcerative colitis and colorectal cancer. A population-based study. N Engl J Med. 1990;323:1228-33.

12. Eaden JA, Abrams KR, Mayberry JF. The risk of colorectal cancer in ulcerative colitis: a meta-analysis. Gut. 2001;48:526-35.

13. Askling J, Dickman PW, Karlen P, Broström O, Lapidus A, Löfberg R, et al. Family history as a risk factor for colorectal cancer in inflammatory bowel disease. Gastroenterology. 2001;120:1356-62.

14. Nuako KW, Ahlquist DA, Mahoney DW, Schaid DJ, Siems DM, Lindor NM. Familial predisposition for colorectal cancer in chronic ulcerative colitis: a case-control study. Gastroenterology. 1998;115:1079-83.

15. Rutter MD, Saunders BP, Wilkinson KH, Rumbles S, Schofield G, Kamm MA, et al. Cancer surveillance in longstanding ulcerative colitis: endoscopic appearances help predict cancer risk. Gut. 2004;53:1813-6.

16. Jones PA, Baylin SB. The fundamental role of epigenetic events in cancer. Nat Rev Genet. 2002;3:415-28.

17. Issa JP, Ottaviano YL, Celano P, Hamilton SR, Davidson NE, Baylin SB, Methylation of the oestrogen receptor $\mathrm{CpG}$ island links ageing and neoplasia in human colon. Nat Genet. 1994;4:536-40

18. Tahara T, Arisawa T. DNA methylation as a molecular biomarker in gastric cancer. Epigenomics. 2015;7:475-86.

19. Issa JP, Ahuja N, Toyota M, Bronner MP, Brentnall TA. Accelerated agerelated CpG island methylation in ulcerative colitis. Cancer Res. 2001;61: $3573-7$

20. Tahara T, Shibata T, Nakamura M, Okubo M, Yamashita H, Yoshioka D, et al. Association between polymorphisms in the XRCC1 and GST genes, and CpG island methylation status in colonic mucosa in ulcerative colitis. Virchows Arch. 2011:458:205-11.

21. Podolsky DK. Inflammatory bowel disease (1). N Engl J Med. 1991;325:928-37.

22. Langholz E, Munkholm P, Davidsen M, Binder V. Course of ulcerative colitis: analysis of changes in disease activity over years. Gastroenterology. 1994; 107:3-11.

23. Arisawa T, Tahara T, Shibata T, Nagasaka M, Nakamura M, Kamiya Y, et al. The influence of promoter polymorphism of nuclear factor-erythroid 2related factor 2 gene on the aberrant DNA methylation in gastric epithelium. Oncol Rep. 2008;19:211-6.

24. Swope MD, Lolis E. Macrophage migration inhibitory factor: cytokine, hormone, or enzyme? Rev Physiol Biochem Pharmacol. 1999;139:1-32

25. Leech M, Metz C, Hall P, Hutchinson P, Ganis K, Smith M, et al. Macrophage migration inhibitory factor in rheumatoid arthritis: evidence of proinflammatory function and regulation by glucocorticoids. Arthritis Rheum. 1999;42:1601-8.

26. Bernhagen J, Calandra T, Bucala R. The emerging role of MIF in septic shock and infection. Biotherapy. 1995;8:123-7.

27. Murakami H, Akbar SM, Matsui H, Onji M. Macrophage migration inhibitory factor in the sera and at the colonic mucosa in patients with ulcerative colitis: clinical implications and pathogenic significance. Eur J Clin Investig. 2001;31:337-43.

28. Donn R, Alourfi Z, De Benedetti F, Meazza C, Zeggini E, Lunt M, et al. Mutation screening of the macrophage migration inhibitory factor gene: positive association of a functional polymorphism of macrophage migration inhibitory factor with juvenile idiopathic arthritis. Arthritis Rheum. 2002;46: 2402-9.

29. Amoli MM, Donn RP, Thomson W, Hajeer AH, Garcia-Porrua C, Lueiro M, et al. Macrophage migration inhibitory factor gene polymorphism is associated with sarcoidosis in biopsy proven erythema nodosum. J Rheumatol. 2002;29:1671-3.

30. Arisawa T, Tahara T, Shibata T, Nagasaka M, Nakamura M, Kamiya Y, et al. Functional polymorphisms in the promoter region of macrophage migration inhibitory factor and chronic gastritis. Int J Mol Med. 2007;20:539-44.

31. Arisawa T, Tahara T, Shibata T, Nagasaka M, Nakamura M, Kamiya Y, et al. Functional promoter polymorphisms of the macrophage migration inhibitory factor gene in gastric carcinogenesis. Oncol Rep. 2008;19:223-8.
32. Nohara H, Okayama N, Inoue N, Koike Y, Fujimura K, Suehiro Y, et al. Association of the $-173 \mathrm{G} / \mathrm{C}$ polymorphism of the macrophage migration inhibitory factor gene with ulcerative colitis. J Gastroenterol. 2004;393:242-6.

33. Rizos H, Darmanian AP, Mann GJ, Kefford RF. Two arginine rich domains in the p14ARF tumour suppressor mediate nucleolar localization. Oncogene. 2000;19:2978-85.

34. Tannapfel A, Busse C, Weinans L, Benicke M, Katalinic A, Geissler F, et al. INK4a-ARF alterations and p53 mutations in hepatocellular carcinomas. Oncogene. 2001;20:7104-9.

35. Poi MJ, Knobloch TJ, Li J. Deletion of RDINK4/ARF enhancer: a novel mutation to "inactivate" the INK4-ARF locus. DNA Repair (Amst). 2017:57:50-5.

36. Shames DS, Minna JD, Gazdar AF. DNA methylation in health, disease, and cancer. Curr Mol Med. 2007;7:85-102.

37. Sato F, Harpaz N, Shibata D, Xu Y, Yin J, Mori Y, et al. Hypermethylation of the p14(ARF) gene in ulcerative colitis-associated colorectal carcinogenesis. Cancer Res. 2002;62:1148-51.

38. Tahara T, Hirata I, Nakano N, Tahara S, Horiguchi N, Kawamura T, et al. Potential link between Fusobacterium enrichment and DNA methylation accumulation in the inflammatory colonic mucosa in ulcerative colitis. Oncotarget. 2017:8:61917-26.

39. Emmett RA, Davidson KL, Gould NJ, Arasaradnam RP. DNA methylation patterns in ulcerative colitis-associated cancer: a systematic review. Epigenomics. 2017;9:1029-42.

40. Hibi K, Nakayama H, Koike M, Kasai Y, Ito K, Akiyama S, et al. Colorectal cancers with both p16 and p14 methylation show invasive characteristics. Jpn J Cancer Res. 2002:93:883-7.

41. Rogler G. Inflammatory bowel disease cancer risk, detection and surveillance. Dig Dis. 2012;30(Suppl 2):48-54.

42. Tahara T, Hirata I, Nakano N, Nagasaka M, Nakagawa Y, Shibata T, et al. Comprehensive DNA methylation profiling of inflammatory mucosa in ulcerative colitis. Inflamm Bowel Dis. 2017;23:165-73.

43. Tahara T, Shibata T, Nakamura M, Okubo M, Yamashita H, Yoshioka D, et al. Host genetic factors, related to inflammatory response, influence the $\mathrm{CpG}$ island methylation status in colonic mucosa in ulcerative colitis. Anticancer Res. 2011;31:933-8.

\section{Publisher's Note}

Springer Nature remains neutral with regard to jurisdictional claims in published maps and institutional affiliations.
Ready to submit your research? Choose BMC and benefit from:

- fast, convenient online submission

- thorough peer review by experienced researchers in your field

- rapid publication on acceptance

- support for research data, including large and complex data types

- gold Open Access which fosters wider collaboration and increased citations

- maximum visibility for your research: over $100 \mathrm{M}$ website views per year

At $\mathrm{BMC}$, research is always in progress.

Learn more biomedcentral.com/submissions 